Thorax 1988;43:739-740

\title{
Surgical management of pneumothorax in cystic fibrosis
}

\section{J SEDDON, M E HODSON}

\author{
From the Cardiothoracic Institute and Brompton Hospital, London
}

ABSTRACT Twenty seven adults with cystic fibrosis who had had either a surgical pleurodesis or pleurectomy for the management of pneumothorax were studied. There were no significant differences in postoperative respiratory function, incidence of recurrent pneumothorax, or incidence of major postoperative complications between the two groups.

The natural history of cystic fibrosis is complicated by a high incidence of pneumothorax, which increases with age; this constitutes an important cause of mortality and morbidity. ${ }^{1-5}$ Pleurodesis or pleurectomy is usually recommended if there is a persistent air leak after seven days' treatment with an intercostal drain or, in the event of a second symptomatic episode, after a short period of antibiotic treatment and intercostal drainage. Thoracotomy is safe even in the presence of severe airways obstruction ${ }^{6-8}$ but it is not clear whether pleurodesis or pleurectomy constitutes the more satisfactory procedure for these patients. ${ }^{90} \mathrm{~A}$ review of our patients with cystic fibrosis submitted to surgical management of pneumothorax is presented in an attempt to clarify this issue.

\section{Methods}

The case notes of 27 patients with cystic fibrosis who underwent a thoracotomy for either pleurodesis or pleurectomy were reviewed. For comparison of perioperative and postoperative data, patients were grouped according to whether they had had a pleurectomy or a pleurodesis.

The following details were abstracted from the case notes: (1) incidence of recurrent ipsilateral pneumothorax; (2) frequency of postoperative complications; (3) preoperative and postoperative respiratory function.

One patient who had had a resection of the right upper lobe at the time of pleurectomy was excluded from analysis. The preoperative data used were those recorded before the onset of the pneumothorax but not longer than a month before surgery.

\section{Results}

Of the 27 patients, nine had surgery to both pleural spaces. The mean $\mathrm{FEV}_{1}$ expressed as a percentage of predicted values was $34 \%$ before operation; no patient had a value greater than $50 \%$ predicted. Three, six and 12 months after operaAddress for reprint requests: Dr D J Seddon, Department of Medicine, Charing Cross Hospital, London W6 8RF.

tion the mean values for all patients were $22 \%, 21 \%$, and $21 \%$.

Pleurectomy Nineteen patients had a total of 22 pleurectomies, in which a variable portion of the parietal pleura was removed. Seven of these patients developed recurrent ipsilateral pneumothorax and in three cases intercostal intubation was required. Three patients had major postoperative complications. Two required surgical removal of a pleural haematoma, and one patient developed cardiac arrhythmias with a fatal outcome.

Pleurodesis Eight patients had 14 pleurodeses. There were four cases of recurrent ipsilateral pneumothorax, two of which necessitated intercostal intubation. One patient inhaled vomit after operation and died. This was the only major postoperative complication in this group.

The differences in frequency of recurrence of the pneumothorax and of complications and in the time from surgery to discharge did not differ significantly between the two groups (table). There was no significant difference between the two groups for either FEV , or forced vital capacity (FVC) three, six, or 12 months after surgery.

\section{Discussion}

Cystic fibrosis is characterised by progressive deterioration in pulmonary function. None of the 27 patients reviewed had a preoperative $\mathrm{FEV}_{1}$ greater than $50 \%$ of the predicted value. Three, six, and 12 months after operation there was no significant difference in FEV, or FVC between the group having pleurectomy and pleurodesis.

Increasing numbers of patients with cystic fibrosis in terminal respiratory failure are being successfully treated by heart-lung transplantation. One of the major problems faced by surgeons has been haemorrhage and difficulty in removing

Outcome in the two groups

\begin{tabular}{llc}
\hline & Pleurectomy & Pleurodesis \\
\hline No of patients & 19 & 8 \\
No of operations & 22 & 14 \\
$\begin{array}{l}\text { FEV (mean \% predicted): } \\
\text { Before operation }\end{array}$ & 35 & 33 \\
After operation: & 27 & 30 \\
$\quad$ 3 months & 28 & 29 \\
$\quad$ 12 months & 29 & 28 \\
Recurrent pneumothorax & 7 & 4 \\
Recurrent pneumothorax requiring & 3 & 2 \\
intubation or surgery & $3\left(1^{*}\right)$ & $1\left(1^{*}\right)$ \\
Postoperative complications & 16 & 13 \\
Days from surgery to discharge & & \\
(mean) & &
\end{tabular}

*Died. 
the lungs from patients who have had previous thoracic surgery. We would currently recommend that a patient with cystic fibrosis with recurrent pneumothoraces who might be a candidate for heart-lung transplantation in the future should be treated with the minimum of intervention. Intercostal tube drainage, chemical pleurodesis, ligation of bullae, or limited surgical pleurodesis should be performed in preference to pleurectomy. When patients are already severely ill, it may be necessary to assess them rapidly for heart-lung transplantation and to try to arrange early transplantation.

We would like to thank our surgical and anaesthetic colleagues for their help in the care of these patients. Miss Sally Hockley kindly prepared the manuscript.

\section{References}

1 Batten JC, Matthew DJ. The respiratory system. In: Hodson ME, Norman AP, Batten JC, eds. Cystic fibrosis. London, Ballière Tindall, 1983.
2 Batten JC. Cystic fibrosis: coming of age. Adv Med 1983; $367-83$.

3 Di Sant'Agnese PA, Davis PB. Cystic fibrosis in adults. Am J 1979;66:121-32.

4 Hodson ME. Cystic fibrosis. Postgrad Med J 1984;60:225-33. $\frac{\hbar}{\sigma}$

5 Luck SR, Raffensperger JG, Sullivan HJ, Gibson LE. Mæagement of pneumothorax in children with chronic pulmongty disease. J Thorac Cardiovasc Surg 1977;74:834-9.

6 Ruckley CV, McCormack RJM. The management of spontane@is pneumothorax. Thorax 1966;21:139-44.

7 Singh SV. Surgical treatment of spontaneous pneumothorax $\overrightarrow{b b y}$ parietal pleurectomy. Scand $J$ Thor Cardiovasc SRg 1982;16:75-80.

8 Weeden J, Smith GH. Surgical experience in the managemen of spontaneous pneumothorax. Thorax 1983;38:737-43.

9 Penketh ARL, Knight RK, Hodson ME, Batten JC. Management of pneumothorax in adults with cystic fibrosis. Thordx 1982;37:850-3.

10 Stone SM, Boat RF, Mendelsohn H, et al. Open thoracotomy for pneumothorax in cystic fibrosis. Am Rev Respir Dis 1975; 111:611-7. 